\title{
Policy Analytics, Household Informedness and the Collection of Household Hazardous Waste
}

\author{
Kustini Lim-Wavde ${ }^{1}$, Robert J. Kauffman ${ }^{1}$ and Gregory S. Dawson ${ }^{2}$ \\ ${ }^{1}$ School of Information System, Singapore Management University, Singapore \\ ${ }^{2}$ W.P. Carey School of Business, Arizona State University, United States of America
}

\begin{abstract}
Proper collection of Household Hazardous Waste (HHW) is an important action to support environmental sustainability. We investigate the role of household informedness, the degree to which households have the necessary information to make utility-maximizing decisions, as they relate to participation in HHW collection programs. We find two factors that influence household informedness: the provision of public education about HHW and environmental quality information. We conducted an empirical study on HHW collection in California to obtain statistical evidence on the effect of these factors on the amount of HHW collected. The findings of this policy analytics study improve our understanding of how household informedness influences household decision-making in participating in HHW collection programs. This study is useful in the guidance it offers to devise new information policies to maximize households' participation in HHW collection program.
\end{abstract}

\section{Introduction}

Household informedness is the degree to which households have the necessary information to make utilitymaximizing decisions in their daily activities, such as managing their home waste. It can also play an important role in the management of Household Hazardous Waste (HHW), particularly in optimizing their collection. Our study is intended to apply policy analytics methods and econometrics related to HHW management in a way that considers the role of household decision-making to improve the household waste management process.

Policy analytics emphasizes value-driven assessment of data for problems involving multiple stakeholders. It offers a framework for: identifying key issues, defining policy objectives, designing and testing policy, evaluating the effectiveness of policy implementation, and adjusting policy [1]. In this research, we analyze household data on HHW collection to obtain evidence on the impact of household informedness for household-level decisions.

In some parts of the world, local governments have organized various HHW collection programs that complement regular trash collection. These collection programs include HHW permanent facilities, load checking of hazardous materials in trash before disposal in landfills, door-to-door programs, mobile facilities, HHW recycling facilities, curbside facilities, and one-day collection events [2]. However, the success of these collection programs relies on voluntary participation of households because they are required to identify the HHW materials, and also to segregate, store, and transfer them to the collection facilities.
A recent review on HHW collection reported that the amount of HHW collected is only about $0.12 \%$ to $1.88 \%$ of total Municipal Solid Waste (MSW) [3]. This estimate is based on data from previous studies conducted in 20 European countries, several states in the U.S, and Mexico, Canada, Greenland, Japan, India, Pakistan, Hong Kong, and Nepal. These numbers do not include HHW that is disposed of improperly, for example, kept in storage rooms, poured into drains or disposed together with trash. The common belief is that the amount of HHW collected may be greater when more households are encouraged to participate in collection programs.

As we improve household informedness, households are likely to make better decisions to optimize their utility with respect to household waste. This, we believe, should lead to beneficial effects to increase the amount of HHW diverted from general trash, and consequently also improve environmental quality. Previous studies attempted to explain household-level decision-making related to their management of waste. Kinnaman and Fullerton [4], for example, developed a household utility maximization model to understand household's disposal and recycling decisions. The authors' model assumes that each household maximizes its utility subject to a budget constraint. Such decisions depend largely on the price or cost of disposal, recycling, or collecting HHW. Sidique et al. [5] adopted this model and added an environmental quality factor in the utility function: households also benefit from environmental quality.

To our knowledge, no researchers have studied the role of household informedness within a utility maximization framework that addresses the collection of 
HHW. This study focuses on a key question related to this. How does household informedness influence household decisions in terms of the amount of HHW collected? We will identify and analyze two important factors that influence household informedness in HHW management: the provision of public education about HHW and the environmental quality information.

\section{Household informedness}

\subsection{HHW public education}

Public education about $H H W$ has long been a part of waste management. We include this as an important part of household informedness because it can decrease the costs of household decision-making. It usually provides information about the potential hazards of corrosive, toxic, reactive or ignitable materials found in common household products. These include batteries, oil-based paints, latex paints, motor oils, cleaning products, pesticides, insecticides, and electronic devices. It also provides information on how to properly store, handle, and dispose these leftover materials. For example, paint cans have to be sealed before storing them in dry areas.

Similarly, pesticides also need to be stored in dry areas in their original containers with their labels intact. The leftover liquids should not be poured into the gutter, drain or put together with regular trash that usually goes to landfills. If they are not handled correctly, the contaminants can either seep into groundwater or be carried off by storm water run-off and eventually pollute public drinking water [6]. Without this kind of information households may pollute the water or land in their neighborhood with those hazardous materials.

This public education also provides information on a range of facilities, programs and events to guide households about the disposal of their HHW. HHW collection often follows certain schedules and depends on the type of facility or program type. HHW permanent facilities may receive HHW all year round, while temporary facilities may only accept waste on certain days of the week. One-day collection events also may be held. Some materials, for example, leftover paints, are accepted by local retail stores in the U.S.

Another objective of public information on HHW is to decrease the use of hazardous materials in households each day. This is achieved by providing information about alternative non-toxic or non-hazardous products that can substitute for the ones that are commonly used; for example, using baking soda with white vinegar to replace chemical oven cleaner. In this way, public education can be used as a source control measure that aims to reduce the generation of HHW at the source [2].

An effective public education program does not only create brochures or posters with such information. In implementation, there are many barriers to changing household-level behavior. A good education program manager will use various strategies to educate households, such as getting involved with them, giving feedback and motivating people, using friends and relatives, finding change agents and role models in the community, and presenting information effectively [7].

Due to the different types of information and methods to deliver it, it is difficult to measure the effects of public education on HHW collection. Empirical researchers often use proxies to quantify conditions that cannot be directly measured. Sidique et al. [5] used three-year cumulative recycling education expenditures to proxy for recycling awareness in Minnesota counties. They applied cumulative expenditures instead of yearly expenditures because of the cumulative effects of recycling education on recycling activities. They found that public education expenditures in recycling had a positive effect, increasing the recycling rate.

In our study, we use HHW public education expenditure as a proxy of household informedness through HHW public education. We believe that this will increase the amount of HHW collected in the short term. While it can act as source control, it will take a longer time for households to change their consumption behavior than what can come from participating in HHW collection programs to dispose of their HHW.

\subsection{Environmental quality information}

Fishbein [8] defined environmental quality as the quality of life within it. It can have different values for different stakeholders, such as conservationists, industrialists, general public, and so on. So it is usually governed by environmental policy in a nation. In our study, we adopt this definition for environmental quality: "varied characteristics such as air and water purity or pollution, noise, access to open space, and the visual effects of buildings, and the potential effects which such characteristics may have on physical and mental health" [9]. An example of environmental quality information is the level of contaminants in water, land, or air, and whether it exceeds the limit that poses a threat to human health as determined by the national environmental agency. This information can be delivered to the public in various formats and channels. A country's national environmental agency usually provides this information via memoranda, mobile applications, or web pages.

In our study, we use direct public notifications to measure household informedness related to environmental quality information. This kind of information is targeted directly to households, so it is most likely to affect their informedness levels related to HHW. Mobile applications or website information may also affect informedness; however, it is difficult to assess whether households have accessed information this way, because their behavior is unobservable.

Previous empirical studies have found that public notification, information disclosure, and advisory announcements related to environmental quality have significant effects on the behavioral changes of targeted consumers and households. For example, Shimshack et al. [10] found that well-informed consumers reduced their canned fish consumption in response to the U.S. Food and Drug Administration's (FDA) mercury advisories. Bennear and Olmstead [11] also found that information 
disclosures on violations in drinking water quality in the form of annual consumer confidence reports for people in Massachusetts reduced total violations between $30 \%$ and 44\%. Zivin et al. [12] also studied the impact of water quality violation information in Northern California and Nevada, but they focused on the costs of avoidance behavior. They estimated the public's willingness-to-pay to avoid water quality violations. In economic terms, when the cost of avoiding water violations is more than the cost of disposing HHW properly via collection programs, households will prefer to participate in HHW collection programs.

Our study uses data on annual consumer confidence reports that contain water quality violations in California. We hypothesize that there is a relationship between perceptions of water quality and the amount of HHWs collected or disposed illegally. As a result, such information disclosure to households will create public awareness about unacceptable water quality to motivate them to participate in HHW collection programs.

\section{Data and empirical model}

\subsection{Data: CalRecycle HHW collection}

We explore and analyze HHW collection data published by California's Department of Resources Recycling and Recovery (CalRecycle) from 2004 to 2012. CalRecycle manages the waste handling and recycling program in California. It conducts annual mandatory survey to collect HHW data from public agencies that manage HHW within their jurisdiction in the county. These agencies submitted their data via CalRecycle Form 303 for the period of July 1 in the first year to June 30 in the following year [13]. The HHW collection report is available to public. It contains information on the reporting agency, report cycle year, material category and type, HHW program type, and the weight of the waste in pounds. We aggregated the data at the county level by summing up the weight of the collected waste in the same county, report cycle year, material category, and program type. We did so because we aimed to understand household waste collection behavior at the county level.

The second data source is the U.S. Census Bureau's American Community Survey [14]. From this source, we obtained California county and demographic characteristics, such as population, density, median age, average household size, rental household rate, unemployment rate, and percent of high school graduates.

Our study uses the U.S. dollar value of HHW grant awards for HHW public education programs as a proxy for HHW public education efforts. The CalRecycle HHW grant database data were obtained were the same in this respect. Similar to Sidique et al. [5], we also assume that public education may have cumulative effect to the following years. Thus, we use the three-year cumulative HHW grant awards for public education. Since the value of the grant awards is not only specifically spent for public education programs, we use a dummy variable instead of continuous variable for HHW public education, with 1 for public education, and 0 if there was none.
For environmental quality information, we use the presence of Maximum Contaminant Level (MCL) violations in the drinking water. The data were obtained from the annual compliance report by the California Department of Public Health. We have the violation counts of MCL in the report; however, we decided to use a $0 / 1$ dummy variable to indicate whether there were any violations because the number of MCL violations may not represent the severity or health risk in household members' perceptions. Under the Safe Drinking Water Act (SDWA) in the U.S., water system companies are required to notify the affected households promptly, whenever there is a violation of drinking water quality regulations. So these data can be good proxy for household informedness through environmental quality information.

Table 1. Description of variables.

\begin{tabular}{|c|c|}
\hline County & County \\
\hline ReportCycle & Report cycle year (2004-2012) \\
\hline HHWCollectionQ & Quantity of HHW collected in pounds \\
\hline HHWMaterial & $\begin{array}{l}\text { Categorical variable for HHW } \\
\text { material categories: flammable and } \\
\text { poison; inorganic and organic acid; } \\
\text { inorganic and organic base; } \\
\text { oxidizers, peroxides, oxidizing acid } \\
\text { and base; PCB-containing; } \\
\text { reclaimable; asbestos; universal } \\
\text { waste; others }\end{array}$ \\
\hline HHWProgramType & $\begin{array}{l}\text { Categorical variable for collection } \\
\text { program types: permanent } \\
\text { facilities, mobile facilities, } \\
\text { temporary or periodic facilities, } \\
\text { door-to-door (residential) } \\
\text { programs, curbside programs, load } \\
\text { checks, others }\end{array}$ \\
\hline EduHS\% & $\begin{array}{l}\text { Population over } 25 \text { years old with } \\
\text { high school diploma in percentage }\end{array}$ \\
\hline UnemployRate\% & Unemployment rate in percentage \\
\hline Density & $\begin{array}{l}\text { County density in thousand square } \\
\text { feet per capita }\end{array}$ \\
\hline Population & County population in million people \\
\hline MedAge & Median age in year \\
\hline Rental\% & Rental household rate in percentage \\
\hline AvgHHSize & Average household size \\
\hline D_HHWEduCum & $\begin{array}{l}\text { Dummy variable to indicate the } \\
\text { presence of cumulative } 3 \text {-year } \\
\text { HHW grant dollar that is used for } \\
\text { projects with public education or } \\
\text { information }\end{array}$ \\
\hline D_MCLviolation & $\begin{array}{l}\text { Dummy variable to indicate the } \\
\text { presence of Maximum } \\
\text { Contaminant Level (MCL) } \\
\text { violations in public drinking water }\end{array}$ \\
\hline
\end{tabular}

We combined the above data into a multidimensional panel with county as an individual dimension, and program type and material category as group dimensions, with report cycle year as the time dimension. A few counties did not have demographic characteristics data in the American Community Survey in some years. So there are some missing values in the panel. After omitting the rows with missing values, there are 7,936 data points covering 39 counties, 11 HHW material categories, and 
10 HHW program types from the report cycle years 2004 to 2012. We used R and its statistical functions for the data processing and analysis [15].

\subsection{HHW collection model}

We model the HHW collection quantity as the function of household informedness and demographic characteristics variables. The panel data contain multiple dimensions so we employ fixed effects or Least Squares Dummy Variable (LSDV) regression. We control for the unobserved time-invariant effects of program types and material categories using HHWProgramType and HHWMaterial dummy variables. County characteristics variables are used to control for county variation. Our model allows for exogenous effects of statewide changes over time. This is controlled by using a dummy variable, ReportCycleYear. In this way, there will be no remaining heterogeneity in the error term due to unobservable effects from program type, material category, and statewide changes over time. We applied a natural log transformation on the dependent variable $H H W$ Collection $Q$ because its distribution is skewed and its standard deviation is much larger than its mean. The econometric model is written as follows.

$$
\begin{aligned}
& \ln \left(\text { HHWCollection }_{\text {cpmt }}\right)=\beta_{0}+\beta_{1} D_{-} H H W E d u C u m_{c t}+ \\
& \beta_{2} D_{-} \text {MCLviolation }{ }_{c t}+\beta_{3} \text { EduHS\% }{ }_{c t}+ \\
& \beta_{4} \text { UnemployRate } \%_{c t}+\beta_{5} \text { Population }_{c t}+ \\
& \beta_{6} \text { Density }_{c t}+\beta_{7} \text { MedAge }_{c t}+\beta_{8} \text { Rental }_{c t}+ \\
& \beta_{9} \text { AvgHHSize }{ }_{c t}+ \\
& \sum_{p=1}^{8} \theta_{p} \text { HHWProgramType } e_{c t}+ \\
& \sum_{m=1}^{11} \gamma_{m} \text { HHWMaterial }_{m c t}+ \\
& \sum_{t=1}^{9} \delta_{t} \text { ReportCycleYear }{ }_{c t}+\varepsilon_{c p m t}
\end{aligned}
$$

The subscripts in Equation (1) are defined as follows: $c=$ county; $p=$ program type; $m=$ material category; $t=$ report cycle year. The description of the variables is given in Table 1.

\section{Results and discussion}

\subsection{Results}

Table 2 provides the coefficient estimates of our model. The coefficient estimate for the dummy variable D_HHWEduCum is negative and significant. This result shows evidence that HHW public education is associated with decreased amount of HHW collection. This may indicate that HHW public education is effective in controlling HHW at the source, so it may influence households to reduce the use of products containing hazardous or toxic materials. This is not what we expecte, but it is interesting, and deserves comment.

The coefficient of the dummy variable $D_{-}$MCLviolation is positive, but not significant. This result suggests that the effect of water quality information is not salient in increasing household participation in HHW collection programs. Households that receive information on MCL violations in drinking water, in our view, ought to

\begin{tabular}{|c|c|c|c|}
\hline VARIABLES & COEF. & & SE \\
\hline Intercept & 8.24 & $* * *$ & 1.37 \\
\hline D_HHWEduCum & -0.22 & $* * *$ & 0.05 \\
\hline D_MCLviolation & 0.03 & & 0.07 \\
\hline \multicolumn{4}{|l|}{ - County Characteristics } \\
\hline$E d u H S \%$ & 1.05 & $*$ & 0.62 \\
\hline UnemployRate\% & -0.04 & $* * *$ & 0.01 \\
\hline Population & 0.26 & $* * *$ & 0.01 \\
\hline Density & 0.11 & $* * *$ & 0.01 \\
\hline MedAge & -0.04 & $* * *$ & 0.01 \\
\hline Rental\% & -3.23 & $* * *$ & 0.59 \\
\hline AvgHHSize & -0.54 & $* * *$ & 0.19 \\
\hline \multicolumn{4}{|l|}{ - Program Type } \\
\hline Door-to-Door Program & -0.08 & & 0.14 \\
\hline HHW Permanent Facility & 3.38 & $* * *$ & 0.14 \\
\hline Load Check & 0.20 & & 0.15 \\
\hline Mobile Facility & 0.27 & & 0.22 \\
\hline Other & 0.27 & $*$ & 0.15 \\
\hline Recycle-only Facility & 1.05 & $* * *$ & 0.16 \\
\hline Temporary Facility & 1.53 & $* * *$ & 0.14 \\
\hline \multicolumn{4}{|l|}{ - HHW Material } \\
\hline Aerosol Containers $(U W)$ & 0.84 & $* * *$ & 0.21 \\
\hline Asbestos & -0.65 & $* * *$ & 0.11 \\
\hline Base & 0.26 & $* * *$ & 0.08 \\
\hline Electronic Devices (UW) & 4.24 & $* * *$ & 0.09 \\
\hline Flammable and Poison & 3.48 & $* * *$ & 0.08 \\
\hline Other & 1.27 & $* * *$ & 0.08 \\
\hline Oxidizer & -0.83 & $* * *$ & 0.09 \\
\hline PCB-containing & -0.93 & $* * *$ & 0.09 \\
\hline Reclaimable & 3.77 & $* * *$ & 0.08 \\
\hline Universal Waste (UW) & 1.86 & $* * *$ & 0.08 \\
\hline \multicolumn{4}{|l|}{ - Report Cycle } \\
\hline 2005 & 0.33 & $* * *$ & 0.09 \\
\hline 2006 & 0.46 & $* * *$ & 0.09 \\
\hline 2007 & 0.51 & $* * *$ & 0.09 \\
\hline 2008 & 0.58 & $* * *$ & 0.09 \\
\hline 2009 & 0.73 & $* * *$ & 0.11 \\
\hline 2010 & 0.83 & $* * *$ & 0.13 \\
\hline 2011 & 0.79 & $* * *$ & 0.14 \\
\hline 2012 & 0.62 & $* * *$ & 0.13 \\
\hline \multicolumn{4}{|c|}{$\begin{array}{l}\text { Note. Model: fixed effects; dep. var.: } \ln \text { (HHWCollec- } \\
\text { tionQ). Base case indicators for the categorical variables } \\
\text { were not estimated. The base cases are Curbside Program } \\
\text { for Program Type, Acid for HHW Material, and } 2004 \text { for } \\
\text { Report Cycle Year. Adj. } R^{2}=0.63 \text {; } \mathrm{SE}=1.704 ; 7,901 \text { d.f.; } \\
\text { signif.: } * * * 0.01, * *<0.05, *<0.10 \text {. }\end{array}$} \\
\hline
\end{tabular}
perceive the quality of the environment to be low, and subsequently increase the amount of HHW collected and may be discouraged from disposing of HHW improperly.
More observational data on environmental quality or other related factors may be necessary to pursue this aspect of our study further.

Table 2. Estimation results.

\subsection{Discussion}

More information may not necessarily give better impact on household's behavior. Shimshak et al. [10], in this study on the impact of mercury advisories, found that the ability to assimilate information (due to higher education) and access to information (via newspapers or other media) were important determinants in the response to the advisory. In our study, we have the percentage of county population who graduated high school as a proxy for a household's ability to assimilate information, but we have 
no data that can proxy for access to information yet.

Shimshak et al. [10] also found that information advisories may produce unintended spillover effects to non-targeted people. In our case, the MCL violation information in one county may also affect people in the neighboring counties. Thus, it makes it difficult to ascertain the precise effects of public information advisories. We are continuing to pursue this as a measurement issue as a result.

Further, the econometric model in this study has not included the potential simultaneity of demand for HHW collection and demand for Municipal Solid Waste (MSW) disposal. The factors that affect MSW generation (e.g., disposal unit pricing) may influence HHW collection, and at the same time, factors that affect collection of HHW (e.g., HHW programs or education) may also affect the amount of MSW. Hong [16] developed a simultaneous equation model based on the household utility maximization model that explicitly accounts for simultaneity between waste generation and recycling. We are exploring the development of this kind of extension to our work, especially the details of the equations and the data requirements. We will report on this aspect of our work-in-progress at the conference.

We also have not corrected the estimation results to deal with possible policy endogeneity. If policy choices are purposeful actions, then it is necessary to control for the factors that lead to policy decisions [17]. Policymaking in waste management may also be done to meet certain collection or recycling targets. In Hong's [16] model, the garbage unit pricing system was viewed as endogenous and had effects on both MSW generation and recycling. Kinnaman and Fullerton [4] also posited that policy choices were influential: they modeled garbage collection fees and curbside recycling as endogenous variables. They employed two-stage least squares (2SLS) regression to correct for the effects of endogenous policy choices. This kind of correction is useful to prevent over or under-estimating the effect of the policy.

Overall, our research gives preliminary evidence on our assertion that household informedness ought to affect household decision-making in HHW management. Our estimation results showed a negative association between HHW public education and the amount of HHW collected. We interpreted this in a positive way though: this may mean that HHW public education discourages households to use products with hazardous materials $-\mathrm{q}$ source control effect in other words. At the same time, we had rather weak statistical evidence to support our belief that information about maximum contaminant level violation in drinking water may encourage more household participations in separating, collecting, and delivering their HHW to appropriate HHW programs or facilities. This aspect of our empirical research is not yet conclusive, so we have more to do.

Further research work also is necessary to claim that there are causal effects of household informedness on HHW collection. We plan to develop a more complex and realistic simultaneous equation model to address the simultaneity of HHW collection and solid waste generation. The new model should consider endogenous policy choices, such as disposal pricing, HHW programs, and public education programs. We further intend to gather more data on environmental quality information that may have influences on household waste handling behavior. More HHW data from other states or other countries are required to generalize our findings on the effects of household informedness.

\section{References}

1. A. Tsoukiàs, G. Montibeller, G. Lucertini, V. Belton, Policy analytics: An agenda for research and practice. EURO J. Dec. Proc., 1, 115-134 (2013)

2. H. F. Lund, McGraw-Hill Recycling Handbook. 21.1-21.29, McGraw-Hill, New York, NY (2001)

3. V. J. Inglezakis, K. Moustakas, Household hazardous waste management: A review, J. Envir. Mgmt., 150, 310-321 (2015)

4. T. C. Kinnaman, D. Fullerton, Garbage and recycling with endogenous local policy, J. Urb. Econ., 48, 419442 (2000)

5. S. F. Sidique, S. V. Joshi, F. Lupi, Factors influencing the rate of recycling: An analysis of Minnesota counties, Res. Cons. Recyc., 54, 242-249 (2010)

6. U.S. Environmental Protection Agency, Proper disposal of household hazardous wastes, Washington, DC (2014)

7. A. Frahm, D. Galvin, G. Gensler, G. Savina, A., Moser, Changing behavior: Insights and applications. Local Hazardous Waste Management Program in King County, King County Water Pollution Control Division, Seattle, WA (1996)

8. G. W. Fishbein, The real meaning of environmental quality, Am. J. Public Health, 59, 2130 (1969)

9. European Environment Agency, Environmental quality (definition), Copenhagen, Denmark (2015)

10. J. P. Shimshack, M. B. Ward, T. K. M. Beatty, Mercury advisories: Information, education, and fish consumption, J. Envir. Econ. Mgmt., 53, 158-179 (2007)

11. L. S. Bennear, S. M. Olmstead, The impacts of the "right to know": Information disclosure and the violation of drinking water standards, J. Envir. Econ. Mgmt., 56, 117-130 (2008)

12. J. G. Zivin, M. Neidell, W. Schlenker, Water quality violations and avoidance behavior: Evidence from bottled water consumption, Amer. Econ. Rev., 101, 448-453 (2011)

13. CalRecycle, Annual reporting: Household hazardous waste collection information, Sacramento, CA (2015)

14. U.S. Census Bureau, American Community Survey, Washington, DC (2012)

15. R Development Core Team, R: A language and environment for statistical computing, R Foundation for Statistical Computing, Vienna, Austria (2008)

16. S. Hong, The effects of unit pricing system upon household solid waste management: The Korean experience, J. Envir. Econ. Mgmt., 57, 1-10 (1999).

17. T. Besley, T. C. Anne, Unnatural experiments? Estimating the incidence of endogenous policies, Econ. J., 110, F672-F694 (2000) 